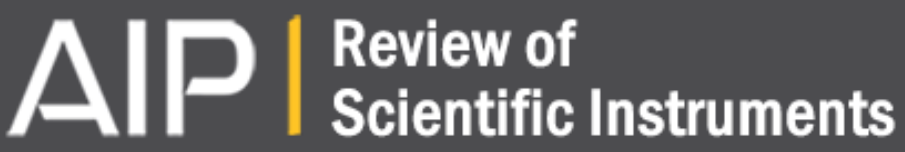

\section{An unload-induced direct-shear model for granular gouge friction in rock discontinuities}

Wei Wu, Yang Zou, Xing Li, and Jian Zhao

Citation: Review of Scientific Instruments 85, 093902 (2014); doi: 10.1063/1.4894207

View online: http://dx.doi.org/10.1063/1.4894207

View Table of Contents: http://scitation.aip.org/content/aip/journal/rsi/85/9?ver=pdfcov

Published by the AIP Publishing

\section{Articles you may be interested in}

Dissipative discrete element model applied to rock avalanches

AIP Conf. Proc. 1542, 638 (2013); 10.1063/1.4812012

Dispersive behavior and acoustic scaling in granular rocks

AIP Conf. Proc. 1542, 559 (2013); 10.1063/1.4811992

Modeling and characterization of laminated granular rocks

AIP Conf. Proc. 1454, 117 (2012); 10.1063/1.4730701

Evaluation Of Fluid Flow Field In Single Rock Fracture During Frictional Sliding

AIP Conf. Proc. 987, 123 (2008); 10.1063/1.2896957

Numerical Evaluation of Anisotropic Fluid Flow in Sheared Rock Fractures

AIP Conf. Proc. 898, 36 (2007); 10.1063/1.2721246

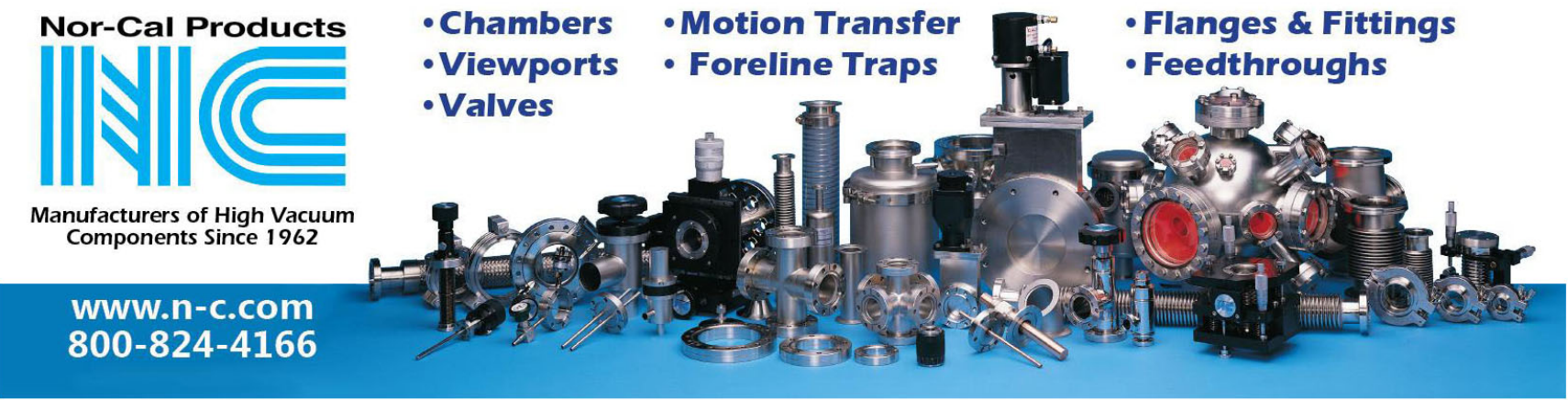




\title{
An unload-induced direct-shear model for granular gouge friction in rock discontinuities
}

\author{
Wei Wu, ${ }^{1, a)}$ Yang Zou, ${ }^{1}$ Xing $\mathrm{Li}^{1}{ }^{1}$ and Jian Zhao ${ }^{2}$ \\ ${ }^{1}$ Ecole Polytechnique Fédérale de Lausanne (EPFL), School of Architecture, \\ Civil and Environmental Engineering, Laboratory of Rock Mechanics (LMR), CH-1015 Lausanne, Switzerland \\ ${ }^{2}$ Department of Civil Engineering, Monash University, Melbourne VIC 3800, Australia
}

(Received 9 May 2014; accepted 18 August 2014; published online 3 September 2014)

\begin{abstract}
The experimental study introduces an unload-induced direct-shear model to investigate the frictional slip of a layer of simulated granular gouges induced by the combination of a decreasing normal stress and a constant shear stress. A frictional equilibrium state of the gouge layer is initially established under fixed normal and shear stresses. The normal stress is proposed to decrease at a constant unloading rate to induce the frictional slip of the gouge layer, and the shear stress is proposed to keep a constant value during the test. A displacement meter and load cells synchronously measure the slip displacement and the applied normal and shear stresses, respectively. The normal and shear stresses sharply decrease with the frictional slip, owing to damage of gouge contacts. The frictional slip is then gradually arrested with new formation of gouge contacts. A greater initial shear stress induces larger normal and shear stress reductions and a smaller slip displacement. The strain energy stored in the discontinuous system before the frictional slip is found to affect the slip displacement. The advantages and the limitations of this model are discussed at the end. (O) 2014 AIP Publishing LLC. [http://dx.doi.org/10.1063/1.4894207]
\end{abstract}

\section{INTRODUCTION}

Knowledge of the frictional slip of pre-existing rock discontinuities has evidently improved over the past 20 years. Such knowledge has made great contributions in underground excavation and in earthquake prediction. Many recent studies consider the frictional slip associated with changes of slip rate and external stress. Acceleration and deceleration of slip rate strongly affect the frictional resistance of rock discontinuities. ${ }^{1-3}$ Shear stress increase is commonly considered to induce the frictional slip of rock discontinuities under a constant normal stress. ${ }^{4,5}$ The frictional slip of rock discontinuities also depends on a variable normal stress, ${ }^{6}$ which has, however, received less attention in previous studies. In rock engineering, underground excavation perturbs an initial stress equilibrium state of rock masses and reduces a tectonic pressure applied to adjacent rocks, which may result in rock collapse $^{7}$ and in induced seismicity. ${ }^{8}$ Our understanding of the frictional slip of rock discontinuities induced by normal stress reduction remains considerably inadequate. Questions regarding the feasibility of rock discontinuity failure, especially how underground excavation increases the probability of the frictional failure of rock discontinuities in adjacent rock masses, remain unanswered.

Filling gouges may exist in all scales of rock discontinuities and strongly influence the frictional responses of rock discontinuities under static and dynamic shear loads. A double direct-shear model has been popularly used to explore the frictional properties of filling gouges under a static shear load. ${ }^{9}{ }^{10} \mathrm{Wu}$ and $\mathrm{Zhao}^{11}$ developed a dynamic-induced directshear model to use an incident P-wave as a dynamic shear

\footnotetext{
a) Author to whom correspondence should be addressed. Electronic mail: wei.wu@epfl.ch. Tel.: +41 216933962. Fax: +41 216934153.
}

load to induce the frictional slip of a layer of simulated granular gouges. The innovative model was able to observe the interaction between seismic wave radiation and frictional slip triggering by recording body waves, slip displacement, and external loads. The model used in this study was modified from the dynamic-induced direct-shear model to simulate the frictional slip of the gouge layer subjected to the combination of a decreasing normal load and a constant shear load.

The triggering mechanism of the frictional slip on a layer of granular gouges can be viewed from a microstructure framework and an energy budget. Majmudar and Behringer ${ }^{12}$ revealed that an inhomogeneous contact network (also called stress chains) forms in granular media to support external stresses. The frictional slip is triggered when stress chains are broken in the media along the slip direction. After broken, stress chains tend to re-form and to re-distribute internal stresses. ${ }^{13}$ Ben-David et al. ${ }^{14}$ presented that the onset of frictional slip is based on the dynamic fracture mechanics. ${ }^{15}$ When strain energy being released exceeds surface energy required for crack extension (also called fracture energy), a crack is introduced and expanded accompanied by energy relaxation. Crack arrest then occurs when released strain energy decreases below fracture energy.

The objective of this study is to introduce an unloadinduced direct-shear model for the frictional slip on a layer of simulated granular gouge. The experimental setup includes a direct-shear configuration with the gouge layer, a normal unloading system, a shear loading system, and a displacement meter and load cells for displacement and load measurements, respectively. The experimental results show the measured normal and shear stresses, the slip displacement, and the coefficient of friction of a typical direct-shear test. We also consider the effect of initial shear stress on the frictional slip of the 


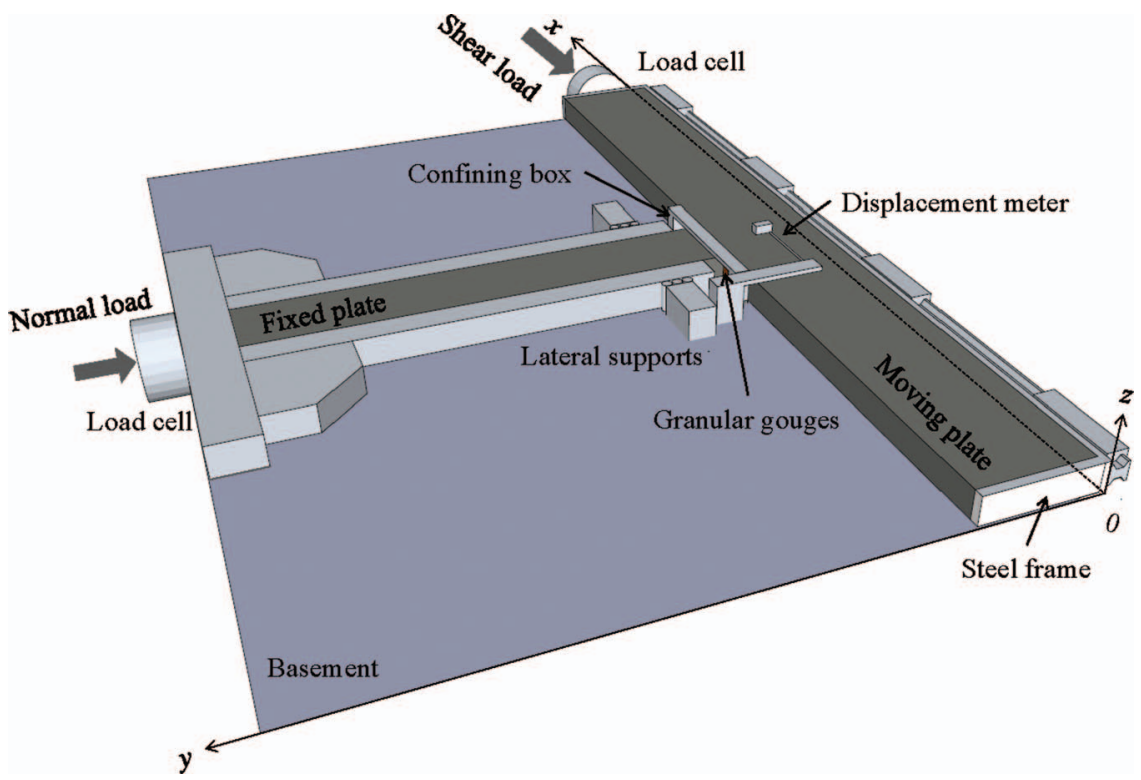

FIG. 1. Schematic view of the unload-induced direct-shear model and the arrangement of a displacement meter and load cells.

gouge layer. To the end, the advantages and the limitations of this model are presented.

\section{EXPERIMENTAL SETUP}

Figure 1 shows a schematic view of the unload-induced direct-shear model. One short side of a fixed plate (size: $500 \mathrm{~mm} \times 80 \mathrm{~mm} \times 30 \mathrm{~mm}$ ) contacted to the center part of one long side of a moving plate (size: $1000 \mathrm{~mm} \times 120 \mathrm{~mm}$ $\times 30 \mathrm{~mm}$ ) through a layer of simulated granular gouges (size: $80 \mathrm{~mm} \times 30 \mathrm{~mm} \times 2 \mathrm{~mm}$ ). A servo-controlled normal stress was applied to the other short side of the fixed plate. A steel frame held the moving plate without the side connected to the fixed plate. The steel frame was connected to the basement through four NSK linear roller guiders. The maximum frictional load of each roller guide was $8 \mathrm{~N}$ for a normal load up to $10 \mathrm{kN}$, which was much smaller than that generated in the gouge layer, and can thus be neglected. A hydraulic jack provided a constant shear stress to one short side of the moving plate. Two lateral supports restricted the fixed plate bending and allowed the fixed plate to move along the $y$ axis.

The high-quality Dark Impala norite was used as the rock medium. The saw-cut unpolished rock surface had a surface roughness of $\sim 5 \mu \mathrm{m}$ (rms). The Young's modulus of the rock material was $63.60 \mathrm{GPa}$ and the shear modulus was $26.50 \mathrm{GPa}$. A layer of air-dry quartz sand in a particle size range of 1-2 $\mathrm{mm}$ was used to simulate granular gouges. The quartz sand was placed in a $2 \mathrm{~mm}$ pre-set gap between the moving and fixed plates and was supported by a steel confining box. The box confined the upper and lower sides of the gouge layer and kept the left and right sides open. Hence, the frictional slip of the gouge layer was considered in the $x-y$ plane.

Figure 1 also shows the arrangement of a displacement meter and load cells. A Philtec fiberoptic sensor was used as the displacement meter to measure the relative displacement of two plates. The displacement meter was fixed on the base- ment and recorded the displacement of the moving plate along the $x$ axis. The laser target was placed at the center of the moving plate to show an average value of the slip displacement. Two load cells were located at the loading points of the normal and shear stresses, respectively. The displacement sensor and load cells were connected to a LabVIEW data acquisition unit and were synchronously measured with a sampling rate of $1000 \mathrm{~Hz}$.

An Abaqus calculation simulated the direct-shear model under the maximum allowable static normal and shear stresses. Figure 2 shows shear stress distribution in two plates and indicates that the shear zone at the end part of the moving plate induced by an initial shear stress of $2.000 \mathrm{MPa}$ has limited interaction with the shear zone at the center part of the moving plate induced by an initial normal stress of 8.000 MPa. Hence, the shear stress at the loading side of the moving plate can be considered to uniformly apply on the gouge layer. Additionally, when we consider seismic wave generation and propagation in the plates in the following study, the long distance between the gouge layer and the plate ends can avoid reflected waves from the plate ends that may affect the slip initiation.

A normal stress and a shear stress were first applied on the gouge layer and were kept constant before the test. During the test, it is proposed that the shear stress remained constant, and the normal stress was constantly decreased to induce the frictional slip of the gouge layer. As shown in Fig. 3, the shear stress is set as a constant value of $0.750 \mathrm{MPa}$ before and during the test. The normal stress is initially set as $4.000 \mathrm{MPa}$. During the test, the normal stress is decreased at an unloading rate of $0.455 \mathrm{MPa} / \mathrm{s}$ until the frictional slip.

\section{RESULTS AND DISCUSSION}

\section{A. Experimental results}

Figure 4 shows that the measured normal and shear stresses are largely different from the proposed normal and 

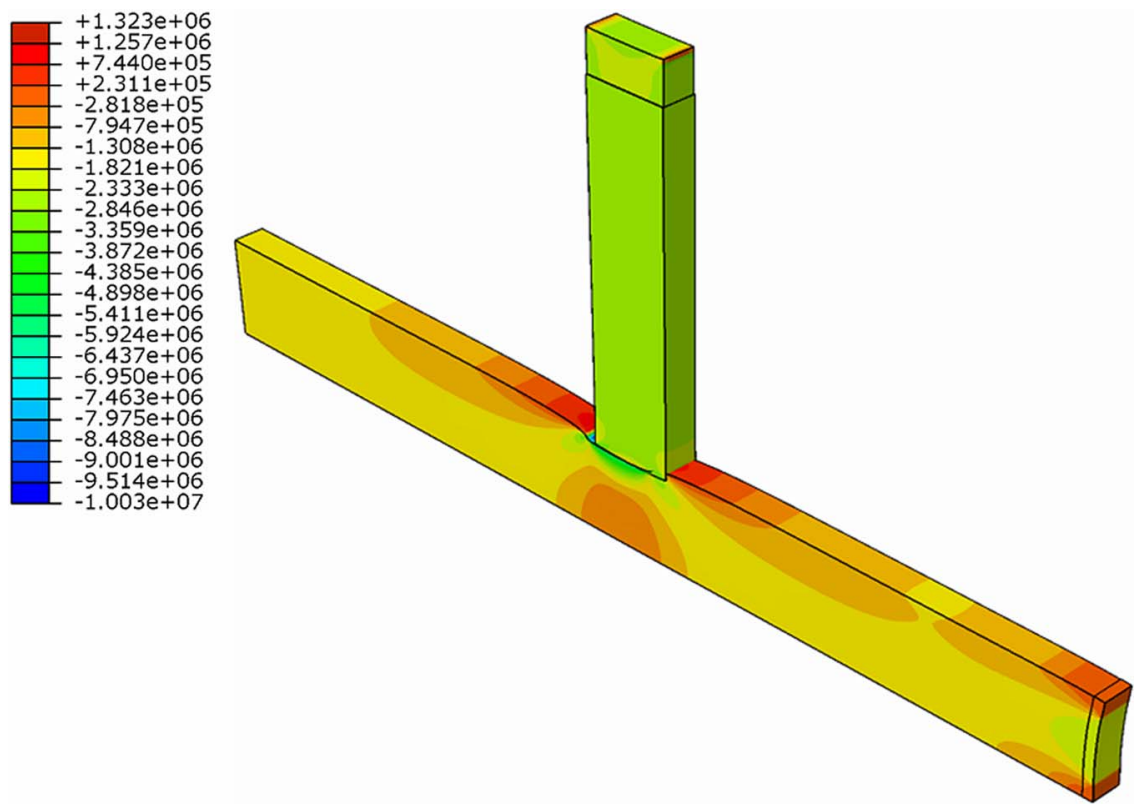

FIG. 2. Shear stress distribution in the plates under the maximum allowable normal and shear stresses (Unit: Pa).

shear stresses when the frictional slip occurs. At the beginning, a frictional equilibrium state of the gouge layer is established under the combination of a normal stress of $4.000 \mathrm{MPa}$ and a shear stress of $0.750 \mathrm{MPa}$. Before the onset of frictional slip, the decreasing normal stress induces a slight reduction of the shear stress from $0.750 \mathrm{MPa}$ at $0.00 \mathrm{~s}$ to $0.675 \mathrm{MPa}$ at $4.00 \mathrm{~s}$. The frictional stress is equal to the applied shear stress. The decreasing normal stress influences the sand compaction state in the gouge layer, resulting in a gradual decrease of the frictional stress between sand grains. Hence, the measured shear stress slightly decreases with decreasing normal stress.

In the first slip event, the normal and shear stresses sharply decrease at about $4.00 \mathrm{~s}$ (Fig. 4). The normal stress decreases from $2.196 \mathrm{MPa}$ at $4.00 \mathrm{~s}$ to $1.214 \mathrm{MPa}$ at $4.10 \mathrm{~s}$. The shear stress reduction is from $0.675 \mathrm{MPa}$ at $4.00 \mathrm{~s}$ to $0.320 \mathrm{MPa}$ at $4.10 \mathrm{~s}$. The normal and shear stress reductions

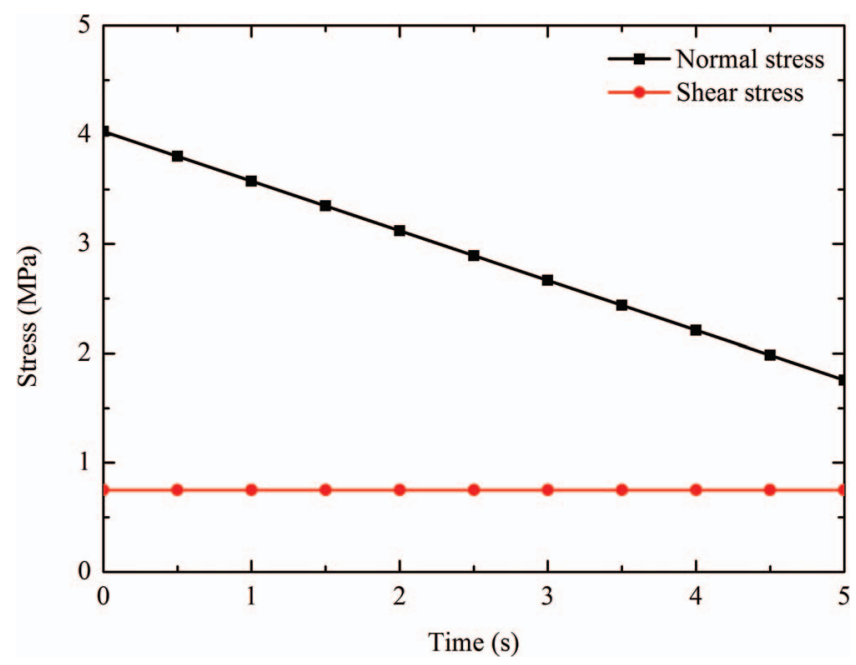

FIG. 3. Proposed decreasing normal stress and constant shear stress applied on the gouge layer during the test. are due to damage of sand contacts, which support external stresses in the gouge layer. ${ }^{12}$ The shear stress reduction is equal to the normal stress reduction multiplied by the coefficient of friction. The shear stress reduction is, thus, smaller than the normal stress reduction. The first slip event greatly varies the sand compaction state, resulting in unloading rate change of the normal stress after the slip event. Hence, we consider the first slip event in this study.

Figure 5 shows the time response of slip displacement during the test. In the first slip event, the slip displacement suddenly jumps from $0.035 \mathrm{~mm}$ at $4.00 \mathrm{~s}$ to $5.475 \mathrm{~mm}$ at $4.10 \mathrm{~s}$ and to $7.020 \mathrm{~mm}$ at $4.20 \mathrm{~s}$. The increase of the slip displacement is due to detachment of sand contacts along the slip direction. Meanwhile, based on an energy budget, elastic strain energy stored in the gouge layer is rapidly released accompanied by damage of sand contacts, when strain energy

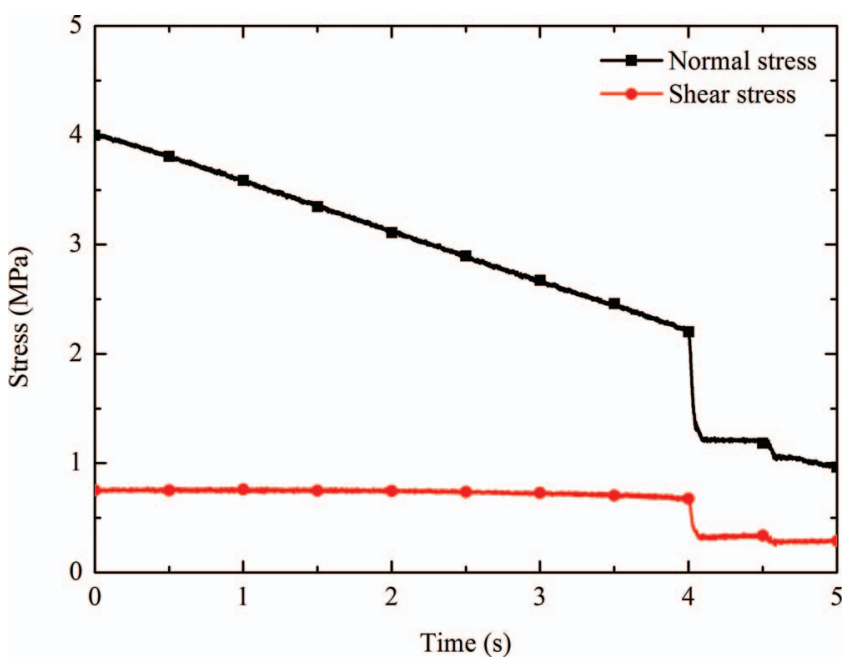

FIG. 4. Measured decreasing normal stress and constant shear stress applied on the gouge layer during a typical test. 


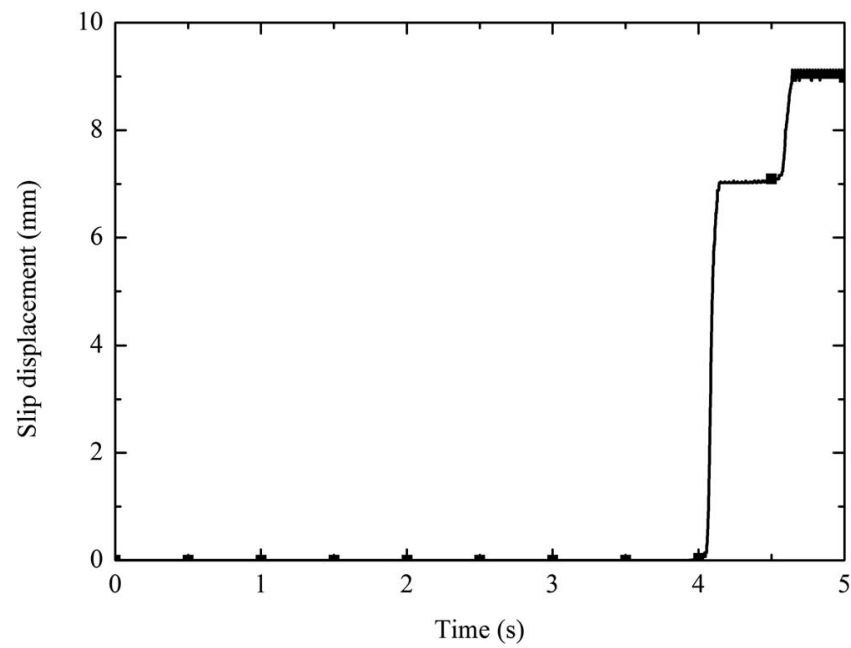

FIG. 5. Time response of slip displacement of a typical test induced by a decreasing normal stress and a constant shear stress.

being released exceeds fracture energy. ${ }^{15}$ The released energy is gradually consumed during the frictional slip. The slip displacement, thus, increases $5.440 \mathrm{~mm}$ in the first $0.10 \mathrm{~s}$ and $1.545 \mathrm{~mm}$ in the second $0.10 \mathrm{~s}$. At the end, the frictional slip is arrested when released strain energy is reduced below fracture energy of newly formed sand contacts.

Figure 6 shows the coefficient of friction as a function of slip displacement during the test. The coefficient of friction is determined by the shear stress over the normal stress. At the beginning, the coefficient of static friction increases to the maximum value of $\sim 0.30$. This process takes the first $4 \mathrm{~s}$ and has nearly no slip displacement along the gouge layer. The increase of static friction is because the normal stress reduction is larger than the shear stress reduction. During the frictional slip, the coefficient of friction is oscillated around 0.27 and is smaller than the coefficient of the maximum static friction. The slip event is in a short duration, but exhibits a large slip displacement. The oscillation of the coefficient of friction is due to continuous change of sand contacts, e.g., detachment and re-connection.

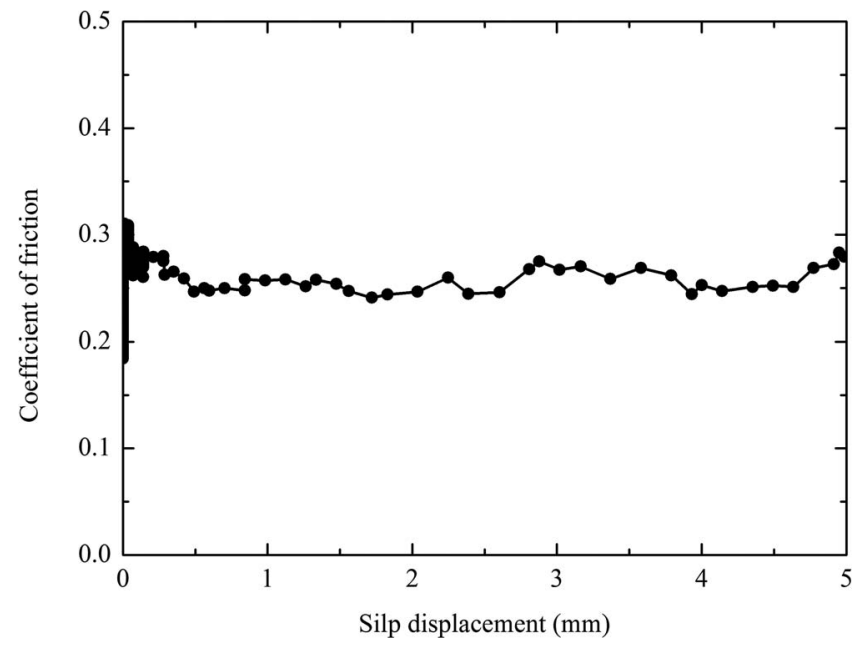

FIG. 6. The coefficient of friction as a function of slip displacement of a typical test.

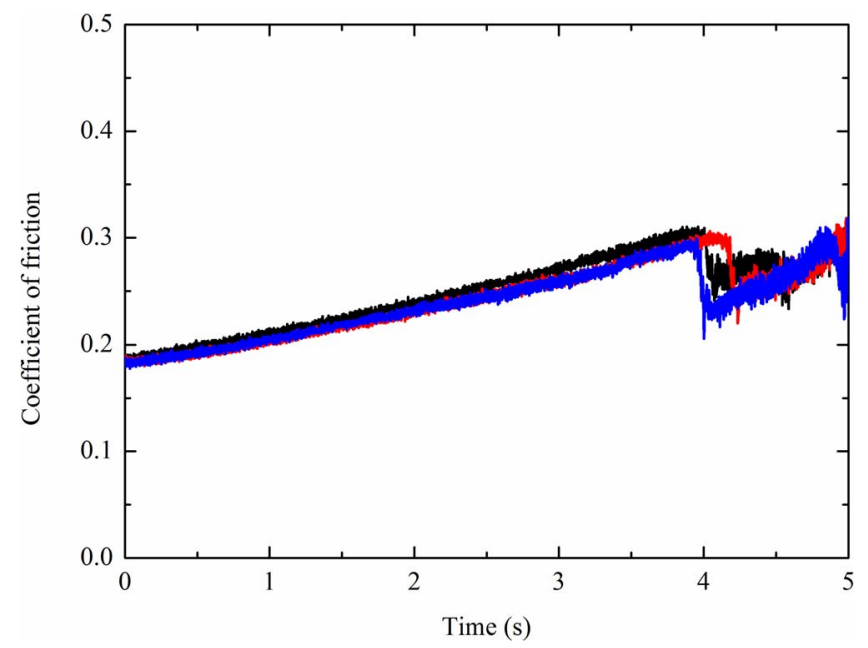

FIG. 7. Time responses of the coefficient of friction of three repeated tests under the same loading condition.

Figure 7 shows the time responses of the coefficient of friction from three repeated tests under the same loading condition as the test above. The coefficient of friction is initially 0.19 and increases to about 0.30 . In the three tests, the reductions of the coefficient of friction appear at about $4.00 \mathrm{~s}$ in the first slip event. It shows the repeatability of the test and the reliability of this model.

\section{B. Effect of initial shear stress}

Three initial shear stresses were considered, namely, $0.250 \mathrm{MPa}$ (Case 1), 0.500 MPa (Case 2), and 0.750 MPa (Case 3). The normal stress was set as the same initial value of $4.000 \mathrm{MPa}$ and the same unloading rate of $0.455 \mathrm{MPa} / \mathrm{s}$, as shown in Fig. 3.

Figure 8 shows the measured normal and shear stresses under three initial shear stresses. A greater initial shear stress induces larger normal and shear stress reductions. For case 1, the normal stress is decreased from $0.620 \mathrm{MPa}$ at $8.30 \mathrm{~s}$ to $0.226 \mathrm{MPa}$ at $8.40 \mathrm{~s}$, and the shear stress is decreased from $0.201 \mathrm{MPa}$ to $0.020 \mathrm{MPa}$. For case 2, the normal stress is de-

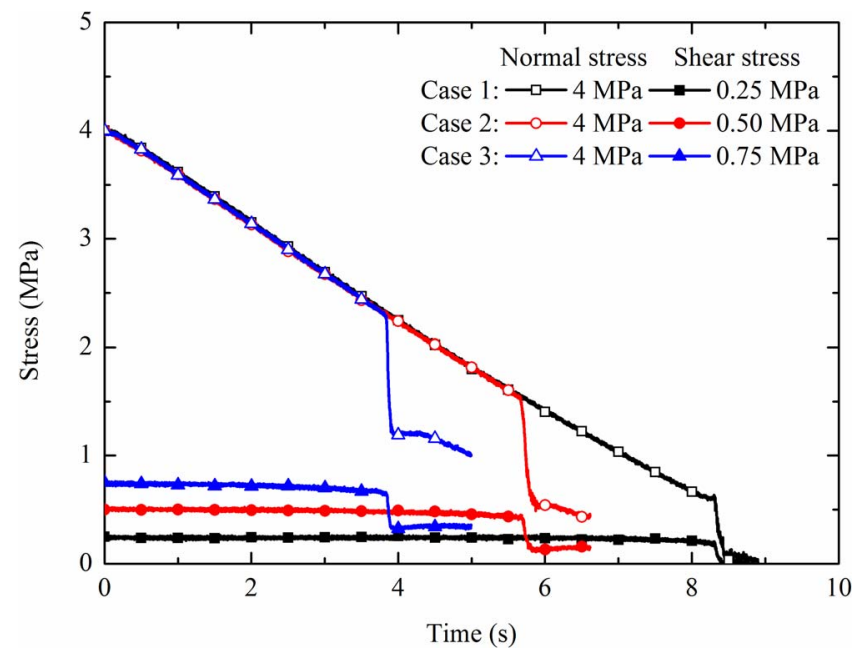

FIG. 8. Measured normal and shear stresses applied on the gouge layer under different initial shear stresses. 


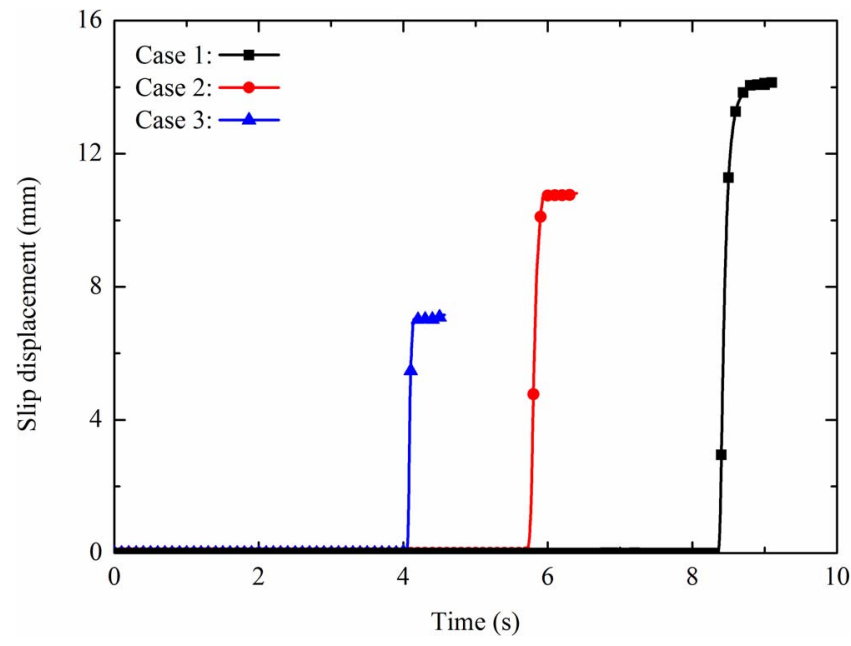

FIG. 9. Time responses of slip displacement under different initial shear stresses.

creased from 1.541 MPa at $5.66 \mathrm{~s}$ to $0.801 \mathrm{MPa}$ at $5.76 \mathrm{~s}$, and the shear stress is decreased from $0.433 \mathrm{MPa}$ to $0.210 \mathrm{MPa}$. For case 3, the normal stress reduction is from $2.287 \mathrm{MPa}$ at $3.83 \mathrm{~s}$ to $1.200 \mathrm{MPa}$ at $3.93 \mathrm{~s}$, and the shear stress reduction is from $0.646 \mathrm{MPa}$ to $0.342 \mathrm{MPa}$. The decreasing normal stress continuously reduces the frictional strength of the gouge layer and induces the frictional slip when the frictional strength becomes equal to or smaller than the initial shear stress. A greater initial shear stress thus reaches the frictional strength of the gouge layer at an earlier time, which remains under a higher normal stress and in a denser compacted state. Hence, damage of sand contacts consumes a greater amount of strain energy, resulting in larger reductions of normal and shear stresses.

Figure 9 shows the time responses of slip displacement under three initial shear stresses. A greater initial shear stress induces a smaller slip displacement. For case 1, the slip displacement is $14.136 \mathrm{~mm}$ in the first slip event. For case 2, the slip displacement is $10.810 \mathrm{~mm}$. For case 3, the slip displacement is $7.160 \mathrm{~mm}$. This observation can be verified by local shear deformation of the adjacent rock before the

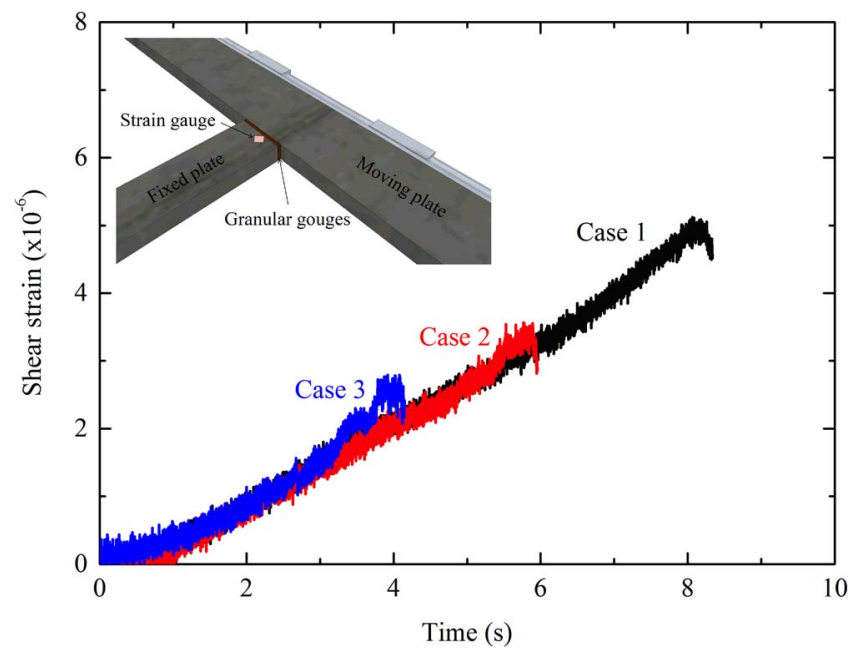

FIG. 10. Local shear deformation of the adjacent rock before the frictional slip. frictional slip. The local shear deformation was estimated by a strain gauge group connected in a full shear bridge, ${ }^{11}$ which was placed at the fixed plate closed to the gouge layer (Fig. 10 inset). As shown in Fig. 10, the unloading normal stress causes the increase of local shear strain at the same increasing rate. When the frictional slip induced by a greater initial shear stress occurs at an earlier time, the shear deformation of the adjacent rock remains in a lower strain level. Hence, less strain energy can be released for the frictional slip and results in a smaller slip displacement.

\section{Advantages and limitations}

The unload-induced direct-shear model simulates the frictional slip on a layer of granular gouges under the combination of a decreasing normal stress and a constant shear stress. The advantages of this model include: (1) synchronously observe normal and shear stress changes before and during the frictional slip; (2) uniformly distribute the normal and shear loads applied on the gouge layer.

The limitations include: (1) owing to an inherent disadvantage of the direct-shear model, shear stress distribution along the gouge layer is not uniform. A small torque caused by the shear load is unable to eliminate and may affect the experimental results to some extent; ${ }^{11}$ (2) the strength of rock plates and the frictional load of roller guides limit the normal stress applied on the gouge layer.

\section{CONCLUSION}

This study introduces an unload-induced direct-shear model to investigate the frictional slip on a layer of simulated granular gouges. The gouge layer is initially in a frictional equilibrium state under fixed shear and normal stresses. The decreasing normal stress induces the frictional slip along the gouge layer under a constant shear stress. The frictional slip is initiated by sharp reductions of the normal and shear stresses. Under the same normal stress unloading condition, the initial shear stress strongly influences the frictional slip of the gouge layer.

Although there are some limitations to be improved, this model provides a possible solution to access the frictional slip of rock discontinuities when underground excavation perturbs an initial stress equilibrium state of rock masses and reduces a tectonic pressure applied to adjacent rocks. The future study will investigate the effects of initial value and unloading rate of the normal stress on the frictional slip of the gouge layer and will consider seismic wave generation and propagation in the plates before and during the frictional slip.

${ }^{1}$ C. Marone, Nature (London) 391, 69 (2011).

${ }^{2}$ G. C. McLaskey, A. M. Thomas, S. D. Glaser, and R. M. Nadeau, Nature (London) 491, 101 (2011).

${ }^{3}$ A. H. Kohli and M. D. Zoback, J. Geophys. Res. 118, 5109, doi:10.1002/jgrb.50346 (2013).

${ }^{4}$ S. C. Bandis, A. C. Lumsden, and N. R. Barton, Int. J. Rock Mech. Min. Sci. Geomech. Abstr. 20, 249 (1993).

${ }^{5}$ D. R. Scott, C. Marone, and S. G. Sammis, J. Geophys. Res. 99, 7231, doi:10.1029/93JB03361 (1994).

${ }^{6}$ M. F. Linker and J. H. Dieterich, J. Geophys. Res. 97, 4923, doi:10.1029/92JB00017 (1992). 
${ }^{7}$ M. C. Stickney and K. F. Sprenke, J. Geophys. Res. 98, 6523, doi:10.1029/92JB02859 (1999).

${ }^{8}$ S. E. Husen, E. Kissling, and A. von Deschwanden, J. Seismol. 17, 63 (2013).

${ }^{9}$ B. M. Carpenter, C. Marone, and D. M. Saffer, Nature Geosci. 4, 251 (2011).

${ }^{10}$ C. Collettini, A. Niemeijer, C. Viti, S. A. F. Smith, and C. Marone, Earth Planet. Sci. Lett. 311, 316 (2011).
${ }^{11}$ W. Wu and J. Zhao, Exp. Mech. 54, 605 (2014).

${ }^{12}$ T. S. Majmudar and R. P. Behringer, Nature (London) 435, 1097 (2005).

${ }^{13}$ N. W. Hayman, L. Ducloue, K. L. Foco, and K. E. Daniels, Pure Appl. Geophys. 168, 2239 (2011).

${ }^{14}$ O. Ben-David, G. Cohan, and J. Fineberg, Science 330, 211 (2010).

${ }^{15}$ L. B. Freund, Dynamic Fracture Mechanics (Cambridge University Press, Cambridge, 1990). 